\title{
Pengertian Borland Delphi Dan Contohnya
}

\author{
DAPOK NOPRIANSYAH \\ 165100074 \\ Fakultas Komputer. $\mathbf{7 8 5 5 6 7 9 2 3}$ \\ dapoknopriansyah.student@umira.ac.id
}

\begin{abstract}
ABSTRAK
ABSTRAK Perencanaan anggaran biaya proyek sangat mutlak dibutuhkan agar proyek yang akan dibangun tidak boros dan sesuai dengan dana yang tersedia. Dahulu pekerjaan menghitung RAB dilakukan secara manual. Satuan harga biaya dan upah dikalikan dengan volume pekerjaan terpakai. Mengerjakan perhitungan RAB secara manual memiliki dua kekurangan utama, yaitu lamban dan memiliki resiko kesalahan yang sangat tinggi. Dengan adanya program komputer, dikembangkan suatu aplikasi untuk menjawab berbagai kendala dalam perhitungan RAB pada umumnya.. Tujuan dari penelitian ini adalah untuk membangun program komputasi RAB untuk bangunan gedung dan tempat tinggal. Program komputasi ini dibuat dengan menggunakan bahasa pemrograman Borland Delphi 7.0 dan database MySQL 4.0. Proses pembuatannya meliputi konsep dan perancangan program yang dibuat berdasarkan perhitungan RAB dengan metode Quantity Take-Off dan Harga Satuan untuk bangunan gedung dan rumah tinggal. Hasil dari penelitian menunjukan bahwa program komputasi RAB Application yang dibuat dengan bahasa pemrograman Borland Delphi 7.0 dan database MySQL 4.0. sangat menghemat waktu dalam melakukan proses perancangan. Kata kunci: Database, Program, Proyek, RAB.
\end{abstract}

Kata Kunci: pengertian borland delphi 7 
A. INTRODUCTION

Materi $\mathrm{Ke} 1$ membahas mengenai i cloud system ...dst tambahkan gambar untuk memperkuat penjelasan ( Gunakan Minimal 400 kata )

Jawab:

\section{Pengertian Borland Delphi Dan Contohnya}

Saya akan share Tentang Delphi yg pasti berguna sih buat Programer mah tapi buat yg tidak tau kan jadi tau dan bisa menambah wawasan dan ilmu pengetahuan karna saya juga belajar dari apa yg saya temukan karna memang saya benar-benar butuh ilmu untuk ekal di masa depan...:)

Delphi adalah sebuah IDE Compiler untuk bahasa pemrograman Pascal dan lingkungan pengembangan perangkat lunak yang digunakan untuk merancang suatu aplikasi program. Delphi juga dapat di artikan sebagai Suatu bahasa pemrograman yang menggunakan visualisasi sama seperti bahasa pemrograman Visual Basic ( VB ). Namun Delphi menggunakan bahasa yang hampir sama dengan pascal (sering disebut objeck pascal) . Sehingga lebih mudah untuk digunakan . Bahasa pemrograman Delphi dikembangkan oleh CodeGear sebagai divisi pengembangan perangkat lunak milik embarcadero . Divisi tersebut awalnya milik borland , sehingga bahasa ini memiliki versi Borland Delphi

Delphi juga menggunakan konsep yang berorientasi objek ( OOP ), maksudnya pemrograman dengan membantu sebuah aplikasi yang mendekati keadaan dunia yang sesungguhnya . Hal itu bisa dilakukan dengan cara mendesign objek untuk menyelesaikan masalah . OOP ini memiliki beberapa unsur yaitu ; Encapsulation ( pemodelan ) , Inheritance ( Penurunan ) , Polymorphism ( Polimorfisme ).

Awalnya bahasa pemrograman delphi hanya dapat digunakan di Microsoft Windows, namun saat ini telah dikembangkan sehingga dapat digunakan juga di Linux dan di Microsoft .NET . Dengan menggunakan free pascal yang merupakan proyek OpenSource, bahasa pemrograman ini dapat membuat program di sistem operasi Mac OS X dan Windows CE.

Umumnya delphi hanya digunakan untuk pengembangan aplikasi dekstop, enterprise berbasis database dan program - program kecil . Namun karena pengembangan delphi yang semakin pesat dan bersifat general purpose bahasa pemrograman ini mampu digunakan untuk berbagai jenis pengembangan software. Dan Delphi juga disebut sebagai pelopor perkembangan RadTool ( Rapid Apllication Development ) tahun 1995 . Sehinnga banyak orang yang mulai mengenal dan menyukai bahasa pemrograman yang bersifat VCL ( Visual Component Library ) ini .

IDE (Integrated Development Environment) adalah program komputer yang memiliki beberapa fasilitas yang diperlukan dalam pembangunan perangkat lunak. Tujuan dari IDE adalah untuk menyediakan 
semua utilitas yang diperlukan dalam membangun perangkat lunak.

Kompilator (Inggris: compiler) adalah sebuah program komputer yang berguna untuk menerjemahkan program komputer yang ditulis dalam bahasa pemrograman tertentu menjadi program yang ditulis dalam bahasa pemrograman lain.

Pascal adalah bahasa pemrograman yang pertama kali di buat oleh Profesor Niklaus Wirth, bahasa Pascal ini sebagai alat bantu untuk mengajarkan konsep pemrograman komputer.

$<$ br

\section{B. Sejarah Borland Delphi}

- Delphi versi 1 (berjalan pada windows 3.1 atau windows 16 bit)

- Delphi versi 2 (Berjalan pada windows 95 atau delphi 32 bit)

- Delphi versi 3 (berjalan pada windows 95 keatas dengan tambahan fitur internet atua web)

- Perkembangan selanjutnya diikuti dengan Delphi versi 4, 5 dan 6.

- Versi terkini dari delphi adalahversi 7 dengan tambahan vitur .net dengan tambahan file XML

\section{Kegunaan Delphi}

- Untuk membuat aplikasi windows

- Untuk merancang aplikasi program berbasis grafis

- Untuk membuat program berbasis jaringan (client/server)

- Untuk merancang program .Net (berbasis internet)
D. Keunggulan Delphi. IDE (Integrated Development Environment) atau lingkungan pengembangan aplikasi sendiri adalah satu dari beberapa keunggulan delphi, didalamnya terdapat menu - menu yang memudahkan kita untuk membuat suatu proyek program. Proses Kompilasi cepat, pada saat aplikasi yang kita buat dijalankan pada Delphi, maka secara otomatis akan dibaca sebagai sebuah program, tanpa dijalankan terpisah. Mudah digunakan, source kode delphi yang merupakan turunan dari pascal, sehingga tidak diperlukan suatu penyesuain lagi.

Bersifat multi purphase, artinya bahasa pemograman Delphi dapat digunakan untuk mengembangkan berbagai keperluan pengembangan aplikasi. E. Adapun sejumlah kelebihan Embarcadero Delphi lainnya, antara lain meliputi:

- Dapat mengkompilasi menjadi single executable (aplikasi portable), memudahkan distribusi dan meminimalisir masalah yang terkait dengan versioning

- Banyaknya dukungan dari pihak ketiga terhadap VCL (biasanya tersedia berikut source codenya) ataupun tools pendukung lainnya (dokumentasi, tool debugging)

- Optimasi kompiler yang cukup cepat

- Mendukung multiple platform dari source code yang sama

- Untuk yang dikelola oleh embarcadero, delphi dapat dijalankan pada multiflatform 
yaitu windows, linux, android, IOS.

\section{F. Ada kelebihan sudah pasti ada kekurangan. Kekurangan dari Delphi antara lain:}

- Partial single vendor lock-in (Borland dapat menetapkan standar bahasa, kompatibilitas yang harus mengikutinya)

- Akses pada platform dan library pihak ketiga membutuhkan file-file header yang diterjemahkan ke dalam bahasa pascal

- Dokumentasi atas platform dan teknik-teknik yang menyertainya sulit ditemukan dalam bahasa pascal (contoh akses COM dan Win32)

\section{G. Langkah - langkah mengaktifkan Delphi 7.}

- Klik start.

- pilih All Programs.

- pilih Borland Delphi.

- pilih dan klik Delphi 7.

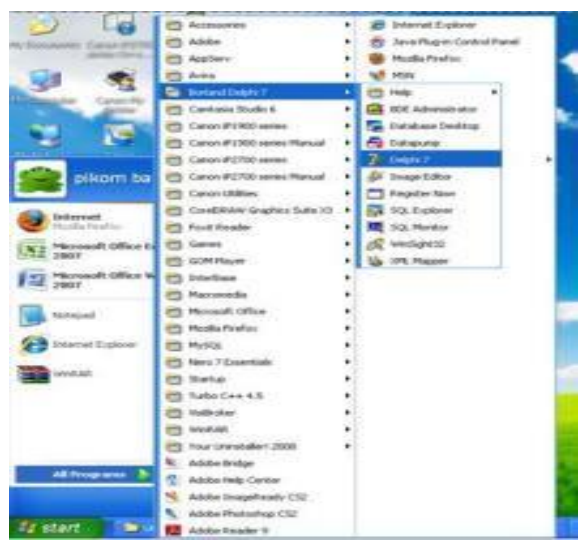

- Jendela Utama Delphi.

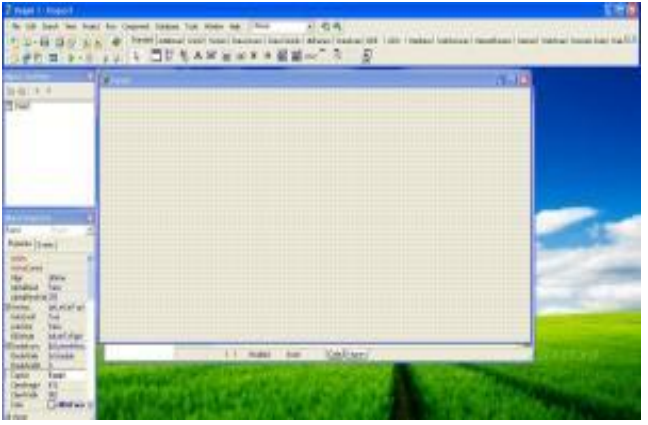

H. Menyimpan Form Pada Delphi ada 3 buah file utama (*.dpr, *.pas, *.dfm)

1. *.dpradalah file proyek yang dibuat berisi program kecil untuk :

- Mendefinisikan unit yang ada didalam file

- Menginisialisasi data

- Membangun Form

- Menjalankan Aplikasi

2. *.pas adalah Unit - unit (Pascal Code File), biasanya terdiri dari satu atau banyak file.

3. *.dfm adalah file definisi Form (Special Pscudo Code File)

Pilih submenu SAVE ALL. Karena kita kadang lupa apakah file unit dan project nya sudah disimpan. dan Delphi akan menanyakan nama file source code untuk unit (*.pas) dan nama file project $(* . \mathbf{d p r})$.

\section{Menjalankan Program}


Jalankan program dengan menekan Tombol F9 atau pilih menu Run kemudian Run. Apabila ada beberapa Form yang ada didalam Project maka kita tentukan dulu form / unit yang akan kita jalankan. caranya yaitu:

Pilih menu project $\Rightarrow$ Options atau tekan tombol Shift + Ctrl + F11 secara bersamaan dan akan tampil jendela Project Option, Silahakan tentukan form mana yang akan dijalankan. Contoh Tampilan Delphi 7.0

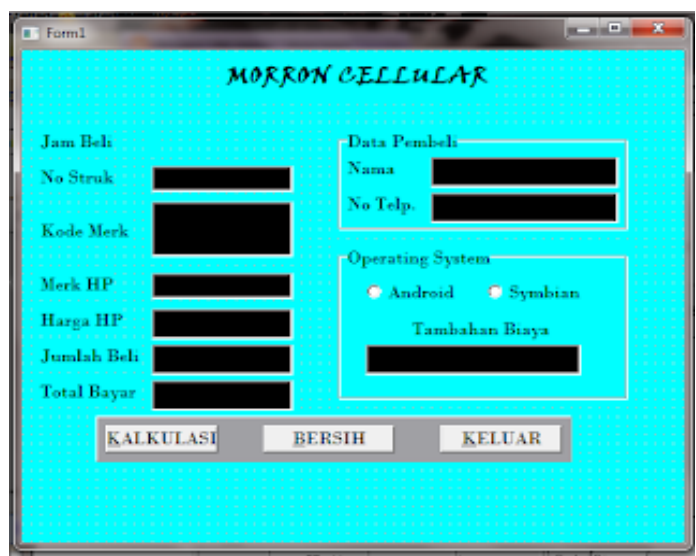

B. CONTENT

Anda Boleh memilih Studi Kasus, Studi Referensi ataupun Studi Penalaran ( Baca: Hal yang akan anda paparkan pada bagian content ini ) ; ex:Materi $\mathrm{Ke} 1$ membahas mengenai i cloud system ...dst tambahkan gambar untuk memperkuat penjelasan ( Gunakan Minimal 600 kata ) \& Reference dibawah Tidak Boleh Dirubah

\section{Contoh studi kasus}

Delphi adalah sebuah IDE Compiler untuk bahasa pemrograman Pascal dan lingkungan pengembangan perangkat lunak yang digunakan untuk merancang suatu aplikasi program. Delphi juga dapat di artikan sebagai Suatu bahasa pemrograman yang menggunakan visualisasi sama seperti bahasa pemrograman Visual Basic ( VB ). Namun Delphi menggunakan bahasa yang hampir sama dengan pascal (sering disebut objeck pascal ) . Sehingga lebih mudah untuk digunakan . Bahasa pemrograman Delphi dikembangkan oleh CodeGear sebagai divisi pengembangan perangkat lunak milik embarcadero . Divisi tersebut awalnya milik borland, sehingga bahasa ini memiliki versi Borland Delphi

Delphi juga menggunakan konsep yang berorientasi objek ( OOP ), maksudnya pemrograman dengan membantu sebuah aplikasi yang mendekati keadaan dunia yang sesungguhnya . Hal itu bisa dilakukan dengan cara mendesign objek untuk menyelesaikan masalah . OOP ini memiliki beberapa unsur yaitu ; Encapsulation ( pemodelan ) , Inheritance ( Penurunan ) , Polymorphism ( Polimorfisme ).

Awalnya bahasa pemrograman delphi hanya dapat digunakan di Microsoft Windows, namun saat ini telah dikembangkan sehingga dapat digunakan juga di Linux dan di Microsoft .NET . Dengan menggunakan free pascal yang merupakan proyek OpenSource, 
bahasa pemrograman ini dapat membuat program di sistem operasi Mac OS X dan Windows CE.

Umumnya delphi hanya digunakan untuk pengembangan aplikasi dekstop, enterprise berbasis database dan program - program kecil . Namun karena pengembangan delphi yang semakin pesat dan bersifat general purpose bahasa pemrograman ini mampu digunakan untuk berbagai jenis pengembangan software. Dan Delphi juga disebut sebagai pelopor perkembangan RadTool ( Rapid Apllication Development ) tahun 1995 . Sehinnga banyak orang yang mulai mengenal dan menyukai bahasa pemrograman yang bersifat VCL ( Visual Component Library ) ini .

IDE (Integrated Development Environment) adalah program komputer yang memiliki beberapa fasilitas yang diperlukan dalam pembangunan perangkat lunak. Tujuan dari IDE adalah untuk menyediakan semua utilitas yang diperlukan dalam membangun perangkat lunak. Kompilator (Inggris: compiler) adalah sebuah program komputer yang berguna untuk menerjemahkan program komputer yang ditulis dalam bahasa pemrograman tertentu menjadi program yang ditulis dalam bahasa pemrograman lain.

Pascal adalah bahasa pemrograman yang pertama kali di buat oleh Profesor Niklaus Wirth, bahasa Pascal ini sebagai alat bantu untuk mengajarkan konsep pemrograman komputer.

\section{CONCLUSION}

Kesimpulan dari materi ini adalah ....( minimal 150 kata $)$

\section{Jawab:}

Kesimpulan ini dikutip dari materi yang telah disajikan penulis pada bab - bab sebelumnya, kesimpulan yang penulis ambil diantaranya sebagai berikut : 1. Kebutuhan program aplikasi di zaman sekarang sangatlah penting.

2. Delphi 7 adalah salah satu software pemrograman berbasis visual yang digunakan untuk membuat program aplikasi pada computer.

3. Bahasa pemrograman yang digunakan di Delphi merupakan turunan dari bahasa pemrograman Pascal. 4. Pada tahun 1992 muncul bahasa pemrograman yang bernama Borland Pascal 7 yang merupakan penggabungan dari Turbo Pascal dan Turbo Pascal for Windows

\begin{tabular}{llr}
5. & \multicolumn{2}{c}{ Borland membuat } \\
bahasa pemrograman baru \\
pada tahun 1995 yang
\end{tabular}


berbasis bahasa pascal. Bahasa pemrograman baru tersebut diberi nama Borland Delphi.

6. ODBC merupakan kepanjangan dari Open Database Connectivity, yaitu seperangkat fungsi untuk melakukan koneksi database secara local maupun remote 7. ODBC mempermudah koneksi aplikasi kebeberapa database yang formatnya berbeda, misalnya format database Ms FoxPro, Ms Access, Ms SQL Server, My SQL ataupun Oracle.

$8 . \quad$ Tujuan dan manfaat
dibuatnya aplikasi
perpustakaan ini yaitu :

\section{DISCUSSION}

Hasil diskusi dari materi ini adalah ....( minimal 150 kata )

Delphi juga menggunakan konsep yang berorientasi objek ( OOP ), maksudnya pemrograman dengan membantu sebuah aplikasi yang mendekati keadaan dunia yang sesungguhnya . Hal itu bisa dilakukan dengan cara mendesign objek untuk menyelesaikan masalah . OOP ini memiliki beberapa unsur yaitu ; Encapsulation ( pemodelan ), Inheritance ( Penurunan ), Polymorphism ( Polimorfisme ).

Awalnya bahasa pemrograman delphi hanya dapat digunakan di Microsoft Windows, namun saat ini telah dikembangkan sehingga dapat digunakan juga di Linux dan di Microsoft .NET . Dengan menggunakan free pascal yang merupakan proyek

OpenSource, bahasa pemrograman ini dapat membuat program di sistem operasi Mac OS X dan Windows CE .

Umumnya delphi hanya digunakan untuk pengembangan aplikasi dekstop, enterprise berbasis database dan program program kecil . Namun karena pengembangan delphi yang semakin pesat dan bersifat general purpose bahasa 
pemrograman ini mampu digunakan untuk berbagai jenis pengembangan software . Dan Delphi juga disebut sebagai pelopor perkembangan RadTool ( Rapid Apllication Development ) tahun 1995 . Sehinnga banyak orang yang mulai mengenal dan menyukai bahasa pemrograman yang bersifat VCL ( Visual Component Library ) ini .

\section{E. REFERENCE}

[1] O. M. Febriani and A. S. Putra, "Sistem Informasi Monitoring Inventori Barang Pada Balai Riset Standardisasi Industri Bandar Lampung," J. Inform., vol. 13, no. 1, pp. 90-98, 2014.

[2] A. S. Putra, "Paperplain: Execution Fundamental Create Application With Borland Delphi 7.0 University Of Mitra Indonesia," 2018.

[3] A. S. Putra, "2018 Artikel Struktur Data, Audit Dan Jaringan Komputer," 2018.

A. S. Putra, "ALIAS MANAGER USED IN DATABASE DESKTOP STUDI CASE DB DEMOS."

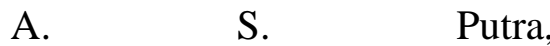
"COMPREHENSIVE SET OF PROFESSIONAL FOR DISTRIBUTE COMPUTING."

[6] A. S. Putra, "DATA ORIENTED RECOGNITION IN BORLAND DELPHI 7.0."

[7] A. S. Putra, "EMBARCADERO DELPHI XE 2 IN GPUPOWERED FIREMONKEY APPLICATION."

[8] A. S. Putra, "HAK ATAS KEKAYAAN INTELEKTUAL DALAM DUNIA

TEKNOLOGY BERBASIS REVOLUSI INDUSTRI 4.0."

[9] A. S. Putra, "IMPLEMENTASI PERATURAN

PERUNDANGAN UU. NO 31

TAHUN 2000 TENTANG

DESAIN INDUSTRI

BERBASIS INFORMATION TECHNOLOGY." 
$\begin{array}{llr}\text { [10] } & \begin{array}{l}\text { A. } \\ \text { "IMPLEMENTATION }\end{array} & \text { Putra, } \\ & \text { OFARADOX DBASE." } & \end{array}$

[11] A

A. S. Putra,

"IMPLEMENTATION OF

TRADE SECRET CASE

STUDY SAMSUNG MOBILE PHONE."

[12] A

S. Putra,

"IMPLEMENTATION

PATENT FOR APPLICATION

WEB BASED CASE STUDI

WWW. PUBLIKLAMPUNG. COM."

[13] A.

"IMPLEMENTATION

SYSTEM FIRST TO INVENT IN DIGITALLY INDUSTRY."

[14] A. S. Putra, "MANUAL REPORT \& INTEGRATED DEVELOPMENT

ENVIRONMENT BORLAND DELPHI 7.0."

[15] A. S. Putra, "PATENT AS RELEVAN SUPPORT RESEARCH."

[16] A. S. Putra, "PATENT FOR RESEARCH STUDY CASE OF APPLE. Inc."

[17] A. S. Putra, "PATENT PROTECTION FOR APPLICATION INVENT."

[18] A. S. Putra, "QUICK REPORT IN PROGRAMMING."

[19] A. S. Putra, "REVIEW CIRCUIT LAYOUT COMPONENT

REQUIREMENT ON ASUS NOTEBOOK."

[20] A. S. Putra, "REVIEW TRADEMARK PATENT FOR INDUSTRIAL TECHNOLOGY BASED 4.0."

[21] A. S. Putra, "TOOLBAR
COMPONENT PALLETTE IN OBJECT ORIENTED PROGRAMMING."

[22] A. S. Putra, "WORKING DIRECTORY SET FOR PARADOX 7."

[23] A. S. Putra, "ZQUERY CONNECTION

IMPLEMENTED

PROGRAMMING STUDI CASE PT. BANK BCA Tbk."

[24] A. S. Putra, D. R. Aryanti, and I. Hartati, "Metode SAW (Simple Additive Weighting) sebagai Sistem Pendukung Keputusan Guru Berprestasi (Studi Kasus: SMK Global Surya)," in Prosiding Seminar Nasional Darmajaya, 2018, vol. 1, no. 1, pp. 85-97.

[25] A. S. Putra and O. M. Febriani, "Knowledge Management Online Application in PDAM Lampung Province," in Prosiding International conference on Information Technology and Business (ICITB), 2018, pp. 181-187.

[26] A. S. Putra, O. M. Febriani, and B. Bachry, "Implementasi Genetic Fuzzy System Untuk Mengidentifikasi Hasil Curian Kendaraan Bermotor Di Polda Lampung," SIMADA (Jurnal Sist. Inf. dan Manaj. Basis Data), vol. 1, no. 1, pp. 21-30, 2018.

[27] A. S. Putra, H. Sukri, and K. Zuhri, "Sistem Monitoring Realtime Jaringan Irigasi Desa (JIDES) Dengan Konsep Jaringan Sensor Nirkabel," IJEIS (Indonesian J. Electron. Instrum. Syst., vol. 8, no. 2, pp. 221-232. 
[28] D. P. Sari, O. M. Febriani, and A. S. Putra, "Perancangan Sistem Informasi SDM Berprestasi pada SD Global Surya," in Prosiding Seminar Nasional Darmajaya, 2018, vol. 1, no. 1, pp. 289-294. 